\section{Estudo \\ cabebate}

em Testão

Planejamento
Revista Estudo \& Debate, Lajeado, v. 28, n. 1, 2021. ISSN 1983-036X

DOI: http://dx.doi.org/10.22410/issn.1983-036X.v28i1a2021.2774

\title{
OS EXCERTOS SOBRE TEORIA E PRÁTICA EVIDENCIADOS PELAS DIRETRIZES CURRICULARES E O ENSINO DA SISTEMATIZAÇÃO DA ASSISTÊNCIA DE ENFERMAGEM
}

\author{
Luís Felipe Pissaia ${ }^{1}$, Márcia Jussara Hepp Rehfeldt ${ }^{2}$, Arlete Eli Kunz da Costa ${ }^{3}$, \\ Claudete Moreschi ${ }^{4}$
}

\begin{abstract}
Resumo: Este estudo possui o objetivo de evidenciar a relação entre teoria e prática no ensino da Sistematização da Assistência de Enfermagem por meio do software Tasy. Neste sentido, realizou-se uma pesquisa qualitativa, descritiva e exploratória. Os instrumentos da pesquisa foram a aplicação de questionário, realização de mapas mentais e o diário de campos dos pesquisadores. Os participantes foram trinta e um estudantes do curso de Enfermagem da Universidade do Vale do Taquari - Univates, matriculados nas disciplinas de Enfermagem na Saúde do Adulto e Idoso I e II. Os achados indicam que os estudantes realizam a Sistematizaçáo da Assistência de Enfermagem em sala de aula, registrando sua compreensão no contexto de utilização. Em consonância, verificou-se que os participantes compreendem o conceito de teoria e prática, bem como suas inter-relaçóes. Sendo assim, percebe-se a importância do uso das tecnologias na compreensão da Sistematização da Assistência de Enfermagem, por meio da facilidade em realizar a relaçáo entre teoria e prática.
\end{abstract}

Palavras-chave: Ensino. Ensino em Enfermagem. Ensino em Saúde. Sistematização da Assistência de Enfermagem. Tasy. Teoria e Prática.

\section{THE EXCERTS ON THEORY AND PRACTICE EVIDENCED BY THE CURRICULAR GUIDELINES AND THE TEACHING OF THE SYSTEMATIZATION OF NURSING ASSISTANCE}

Abstract: This study aims is to evidence the relationship between theory and practice in the teaching of nursing care systematization through the Tasy software. In this way, a qualitative, descriptive and exploratory research was held. The research instruments were the application of a questionnaire, realization of mental maps and the

1 Enfermeiro. Mestre e Doutorando em Ensino. Universidade do Vale do Taquari - Univates. Lajeado - Rio Grande do Sul - Brasil. E-mail: lpissaia@universo.univates.br

2 Doutora em Informática na Educaçáo. Universidade do Vale do Taquari - Univates. Lajeado - Rio Grande do Sul - Brasil. E-mail: mrehfeld@univates.br

3 Enfermeira. Doutora em Ambiente e Desenvolvimento. Universidade do Vale do Taquari - Univates. Lajeado - Rio Grande do Sul - Brasil. E-mail: arlete.costa@univates.br

4 Enfermeira. Doutora em Ciências: Ambiente e Desenvolvimento. Universidade Regional Integrada do Alto Uruguai e das Missóes - URI. Santiago - Rio Grande do Sul - Brasil. E-mail: clau_moreschi@yahoo.com.br 
researchers' field diary. The participants were thirty-one students enrolled in the disciplines of Adult and Elderly Health Nursing I and II of the Nursing course of the University of Vale do Taquari - Univates. The findings indicate that students perform Nursing Care Systematization in the classroom, recording their understanding in the context of use. In agreement, it was verified that the participants understand the concept of theory and practice, as well as their interrelationships. Thus, it's possible to realize the importance to use the technologies in the understanding of Nursing Care Systematization, through the ease in realizing the relation between theory and practice.

Keywords: Teaching. Teaching in Health. Teaching in Nursing. Theory and practice. Tasy. Systematization of nursing care.

\section{Introduçáo}

Como ensinamos a Sistematização da Assistência de Enfermagem (SAE) aos futuros enfermeiros? Há manual de instruçôes? Por momentos, não conseguimos o resultado esperado e como fazer neste caso? Oportunizar que o estudante possa relacionar a teoria e prática é uma alternativa! A reflexão encontra-se embasada na obrigatoriedade das Instituiçóes de Ensino Superior (IES) oferecer aos estudantes a oportunidade de relacionar teoria e prática, incentivando assim, uma formação efetiva na área da enfermagem. No entanto, adianta-se que quando realizamos práticas de ensino, as mesmas não oferecem certeza de compreensão pelos estudantes. Desta forma, é necessário inovar, buscar recursos diferenciados e experienciar a relação entre teoria e prática atentando-se para os resultados gerados pela experiência.

Retomando o termo "experienciar", do ponto de vista de Andrade e Silva (2017), o ensino de enfermagem, principalmente no Brasil, buscou compreender e testar diferentes modelos e práticas acadêmicas as quais embasaram a construção das diretrizes curriculares que ocorreram de forma sistemática e crescente, conforme a profissão foi se estabelecendo na sociedade como integrante de uma área ampla na frente de trabalho em saúde. Dessa forma, o ensino de enfermagem contemporâneo é fruto de um desenvolvimento contínuo e histórico que se incorpora à sociedade brasileira. Conforme Paurosi et al (2018), permeia as transformações impulsionadas pelas mudanças políticas e econômicas da população que influenciaram o modo de compreender o cuidado como um serviço prestado aos clientes, desmistificando as concepçóes antiquadas da caridade oferecida aos enfermos.

$\mathrm{Na}$ opinião de Andrade e Silva (2017), a enfermagem brasileira teve seu início no país em 1923, com o Serviço de Enfermeiras do Departamento Nacional de Saúde Pública (DNSP), instituído por Carlos Chagas e oficializado pelo Decreto no 16300 do mesmo ano, que posteriormente passou a chamar-se de Escola Anna Nery. As primeiras turmas de formadas na Escola foram com o intuito de combater as epidemias que assolavam as grandes cidades brasileiras, principalmente o Rio de Janeiro (ANDRADE; SILVA, 2017). Entretanto, Teixeira (2017) relembra que a instituição era gerenciada por enfermeiras norteamericanas cedidas pela então Fundação Rockefeller, sendo estas profissionais detentoras de um perfil essencialmente hospitalar, contrariando as perspectivas de atuação efetiva em saúde pública, conforme fomentado por Chagas. Ainda para Teixeira (2017), o propósito da Escola previsto por Chagas era a formação norteada pelos preceitos baseados nas necessidades socioambientais da época. Contudo, a Fundação responsável pela Escola Anna Nery, instituiu um currículo composto por trinta e cinco disciplinas, das quais apenas quatro 
eram nesta área, e as demais se embasavam na construção de teoria e prática hospitalar centrada no tratamento de doenças.

Os currículos das escolas que surgiram na sequência seguiram limiares majoritariamente restritos ao modelo biomédico. Contudo, Paulino et al (2017) mencionam que, em meados de 1980, com a ascensão de novas teorias de enfermagem, dentre as quais a de Wanda Horta, iniciaram-se novas discussōes e a introdução de um modelo de formação generalista, fundamentado em novos pilares, agora embasados pela integralidade, equidade e universalidade, presentes nas novas políticas públicas de saúde da época. Passadas algumas décadas, em meados de 1994 a Associação Brasileira de Enfermagem (ABEn), em conjunto com instituiçôes de ensino e saúde, oficializou a Portaria 1721, estabelecendo a formação de enfermeiros em áreas distintas de assistência, gerência, ensino e pesquisa fundamentandose na oferta de um ensino que correlacione a teoria e a prática em compromisso com a sociedade (DUARTE; VASCONCELOS; SILVA, 2017; HORTA, 1974; MARINHO, et al. 2020; ARAÚJO, et al.).

Alguns anos mais tarde, em dezembro de 1996, é instituída a Lei de Diretrizes e Bases da Educação Nacional (LDB) ou Lei no 9.394, que segundo Paurosi et al (2018) implementa mudanças nos currículos dos cursos de graduação em nível nacional, dentre as quais a autonomia das IES a desenvolverem suas matrizes curriculares a partir de suas demandas locorregionais, tendo como ressalva as bases instituídas pela mesma. Conforme Teixeira (2017), as bases oferecidas pela LDB compreendem os conceitos políticos, metodológicos e filosóficos que devem nortear a elaboração dos projetos pedagógicos e instituir planos de ação próprios do ensino em enfermagem.

Em resumo, as diretrizes curriculares preconizam o fortalecimento e desenvolvimento de açóes entre a relação citada de teoria e prática, utilizando-se de diferentes ferramentas e modelos metodológicos com a finalidade da aprendizagem dos estudantes (MAGALHÂES et al., 2017). Em consonância, Andrade e Silva (2017) destacam que a LDB fortalece a autonomia do estudante, responsabilizando-o pelo desenvolvimento de suas competências, que englobam a compreensão de seu contexto social e a capacidade de inserir-se criticamente nele, de maneira que, sentindo-se parte do meio, o indivíduo verifique conscientemente as demandas que a ele são confiadas.

Utilizando-se da argumentação anterior, as políticas públicas demonstraram preocupação ao complementar a LDB de 1996, sendo que o CNE instituiu em 2001 as Diretrizes Curriculares dos Cursos de Graduação em Enfermagem, as quais definem as competências e habilidades gerais para os profissionais, sendo a Atenção à Saúde; Tomada de Decisóes; Comunicação; Liderança; Administração e Gerenciamento e Educação Permanente (CONSELHO NACIONAL DE EDUCAÇÃO, 2001). Como descrito anteriormente, as competências e habilidades desempenham um papel fundamental na formação do profissional de enfermagem, compondo as características mínimas desejadas para exercer suas funçôes dentro de qualquer serviço de saúde, haja vista a formaçáo generalista conceituada anteriormente (CONSELHO NACIONAL DE EDUCAÇÃO, 2001).

O CNE (2001) reforça ainda o papel das IES na formação dos profissionais de enfermagem a partir da contextualização sociocultural correlacionando teoria e prática com 
auxílio de ferramentas tecnológicas que ofereçam o subsídio para o desenvolvimento de um perfil generalista, reflexivo e crítico com sua realidade. Ainda conforme Pissaia et al (2017), o desenvolvimento tecnológico compóe uma demanda notória da sociedade contemporânea, sobretudo em simplificar os processos de trabalho e angariar mais qualidade na assistência à saúde da população.

Neste sentido, a relação entre teoria e prática é instituída como ferramenta eficaz para o ensino de processos próprios da área de enfermagem, dentre os quais, a SAE que conforme Pissaia et al (2018) constitui-se como uma metodologia de trabalho do enfermeiro, cujo processo de compreensão está diretamente relacionado a sua utilização efetiva na assistência oferecida para a populaçáo. Para Tannure e Pinheiro (2014) a SAE é uma metodologia de trabalho privativa do enfermeiro, a qual compreende o levantamento sistemático de informaçóes que compreendem o histórico, os diagnósticos de enfermagem, a prescrição de enfermagem, a implementação do plano de cuidados e a avaliação da assistência. Por esse motivo, Pissaia et al (2018) reafirmam a potencialidade dos significados oferecidos ao tema ao trabalhar-se com a contextualização da SAE em momentos teóricos e práticos, sendo que o estudante torna-se o ator de sua própria aprendizagem.

Neste sentido, o objetivo deste estudo é evidenciar a relação entre teoria e prática no ensino da Sistematização da Assistência de Enfermagem por meio do software Tasy em uma turma de estudantes de enfermagem.

\section{Materiais e Métodos}

Trata-se de uma pesquisa qualitativa, descritiva e exploratória. Este modelo de pesquisa possui aproximaçóes com os preceitos de Moreira (2011), Lakatos e Marconi (2011) e Gil (2008) intuindo sobre a imparcialidade de sua abordagem.

A pesquisa foi realizada no primeiro semestre de 2018, na Universidade do Vale do Taquari - Univates, localizada na cidade de Lajeado, interior do estado do Rio Grande do Sul, Brasil. Os participantes foram trinta e um estudantes do curso de Enfermagem da referida instituição, os quais se encontravam regularmente matriculados nas disciplinas de Enfermagem na Saúde do Adulto e Idoso I e II, teoria e prática. A disciplina faz parte da matriz curricular do quinto semestre do presente curso de graduação, sendo que, os participantes possuíam uma idade média de 24 anos. A referida disciplina possui 80 horas aula e a inserção da pesquisa foi no conteúdo que trata sobre a SAE, correspondendo às 20 horas, sendo os próprios pesquisadores que conduziram as aulas.

A coleta dos dados ocorreu em 20 horas em sala de aula e nas dependências do Centro Clínico Univates, serviço escola da instituição que desempenha o papel de apoio acadêmico aos estudantes e oferece atendimentos multidisciplinares à população regional por meio do Sistema Único de Saúde (SUS). Para a coleta das informaçóes, utilizou-se a aplicaçáo de um questionário nas primeiras quatro horas de atividade na disciplina teórica contendo cinco questóes abertas de cunho descritivo que buscavam responder ao objetivo do estudo, contando com aproximaçóes de Lakatos e Marconi (2011) e Bardin (2016). O questionário solicitava os conceitos e significados sobre a SAE e a sua utilização com o software Tasy. Utilizou-se também da realização de mapas mentais em quatro horas do segundo dia de 
atividades na disciplina teórica, os quais foram construídos em grupos, onde se instigou a reflexão e incorporação de conceitos da SAE pelos participantes, conforme prevê Moreira (1999), além de excertos do diário de campo utilizado pelos pesquisadores que permeou a carga horária total do acompanhamento das disciplinas, observando o comportamento dos estudantes.

Para a realização da pesquisa, aguardou-se a Carta de Anuência da Universidade do Vale do Taquari e do Centro Clínico Univates. Foram seguidos os preceitos para pesquisas com seres humanos conforme a Resolução 466/12 (BRASIL, 2012). Atentou-se também para a utilizaçáo de codinomes aos participantes, sendo utilizado o prefixo "Q" seguido de números ordinais sorteados aleatoriamente. Todos os participantes tiveram conhecimento sobre os objetivos da pesquisa em uma apresentação especialmente realizada pelos pesquisadores, além de ler o Termo de Consentimento Livre e Esclarecido (TCLE), sendo assinado em duas vias individuais pelos participantes e pesquisadores.

Em posse de todos os instrumentos elencados, os pesquisadores realizaram sua transcrição e posterior análise. Durante a análise utilizou-se aproximações com a Análise de Conteúdo, de Bardin (2016), sendo identificados pontos focais, os quais por meio da compatibilidade delimitaram a criação de categorias de análise e discussão dos achados.

\section{Resultados e Discussão}

Nesta seção, apresentam-se os resultados compilados a partir da análise dos instrumentos, os quais foram reunidos em duas categorias temáticas. Na primeira categoria intitulada "A construção de conceitos: A percepçáo dos estudantes sobre a relação entre teoria e prática", verifica-se a conceitualização dos participantes sobre a relação entre teoria e prática. Já na segunda, analisam-se as percepções dos participantes vivenciadas sobre a relação entre teoria e prática durante a disciplina investigada, sendo denominada "A construção de conceitos: o que vivenciei no contexto de relação entre teoria e prática na disciplina".

\subsection{A construçáo de conceitos: a percepçáo dos estudantes sobre a relaçáo entre teoria e prática}

Nos cursos de enfermagem, a relação entre teoria e prática coexiste na própria construção curricular firmada a partir das demandas do próprio $\mathrm{CNE}$, basicamente por meio da disposiçẫo de disciplinas teóricas concomitantes às práticas. O intuito desta disposiçãoo disciplinar é que ocorra um compartilhar de conhecimento entre ambos os espaços de ensino. $\mathrm{O}$ estudante é convidado a assimilar determinado conteúdo em sua teoria e em seguida colocá-lo em prática, conferindo assim, significados e uma possível aprendizagem.

Para Andrade e Silva (2017) a construção de um arcabouço teórico e prático fortalece a formação em enfermagem, haja vista a qualificação desejada pelo mercado de trabalho. Para Pissaia e Beschorner (2016), a condução desse modelo formativo, pressupóe a utilização de tecnologias educacionais que alicercem as práticas de ensino e aprendizagem, sendo apostado na relação entre teoria e prática.

No entanto, torna-se constante o questionamento se os estudantes compreendem o significado da relaçáo entre teoria e prática, bem como se o percebem no contexto de sua 
formação acadêmica. Sendo assim, incentivou-se aos participantes da pesquisa a realizarem uma reflexão inicial sobre a "relação entre teoria e prática" no momento acadêmico atual e relatassem em questionário específico.

Inicialmente os participantes descreveram a relação entre teoria e prática de forma conceitual, ou seja, delimitaram seus conceitos por meio de itens destacados como pode ser observado na resposta de Q13: "TEORIA: São aulas de determinada matéria, como acontece o funcionamento da mesma; PRÁTICA: Quando é aplicado num campo em pessoas". Sob o mesmo limiar, Q24 descreve: "Na teoria aprendemos todos os passos metodológicos e corretos de ser feito e na prática aplicamos os nossos conhecimentos". Nos dois relatos, percebe-se que os participantes determinam os dois espaços, o primeiro para um ambiente mais formal e o segundo para uma possível aplicação do mesmo, sendo uma boa base inicial de seus conceitos.

Conforme as próprias Diretrizes Curriculares dos Cursos de Graduação em Enfermagem a relaçáo entre teoria e prática se faz continuamente, de maneira que o estudante esteja revisitando diversas fontes de conhecimento ao mesmo tempo e colocandoas em prática (CONSELHO NACIONAL DE EDUCAÇÃO, 2001). Para Teixeira (2017), a construção histórica do ensino de enfermagem, principalmente no Brasil é alavancada por práticas hospitalares, mas que pouco detinha de momentos teóricos. Dessa forma, a identificação de ambos os contextos de ensino e aprendizagem torna-se um avanço para a área.

Sob estes pressupostos Q24 complementa com um exemplo: “Exemplo: Teoria do Autocuidado, na prática será estipulado o autocuidado, porque através de um estudo teórico foi constatado que funciona". Outro exemplo complementar foi descrito por Q09: "O estágio de Saúde do Adulto e Idoso I: Na aula teórica aprendemos a forma correta de aplicar e desenvolver a SAE e no estágio realizamos as etapas com o paciente”. Ambos os exemplos demonstram um reflexão objetiva sobre o tema, partindo de um esforço individual em demonstrar sua compreensão. Para Pissaia e Beschorner (2016), a identificação de fatores integrantes da relação entre teoria e prática fundamenta o papel do estudante enquanto sujeito de sua própria aprendizagem, interagindo com os conteúdos e partilhando de seus anseios.

Estando sob mesmo limiar, Q14 realiza uma afirmação interessante, pois correlaciona à importância de ocorrer a teoria e a prática em função da qualificação do ensino, segue o relato: "A teoria é essencial, mas a prática é indispensável uma vez que sem ela não saberemos prestar a assistência ao paciente”. A mesma preocupação pela qualificação do ensino é comentada por Q19: "A teoria é a base de tudo, fundamenta todos os estudos realizados na área, inclusive esse estudo servirá para melhorar o ensino, e isso que precisamos de forma que nos formemos melhor no final'. A qualificação do ensino parte integralmente da condução linear da teoria e prática em aplicação pelo estudante, e segundo Magalhães et al (2017), a repercussão dessa junção traz a tona a reflexão crítica dos envolvidos, tornando-os capacitados.

A segurança das práticas desenvolvidas também é atentada por Q27 em sua descrição: " $N$ a teoria temos todas as melhores formas de aprender o que faremos e na prática, por exemplo, para fazer a punção venosa, antes temos que aprender o que é, para que serve, quais os tipos de agulha e depois fazer em pessoas". Esta reflexão representa uma auto avaliação sobre o 
próprio momento em que o participante se encontra, demonstrando a importância desta correlação. $\mathrm{O}$ mesmo ainda complementa: "Na teoria temos artigos, livros, ensinamentos que nos prepararāo para fazer uma boa prática, pois sem estudo, não conseguiremos fazer nada, nem muito menos entender o porquê e como fazer". Tal descrição fomenta ainda mais a preocupação e necessidade de teoria e prática estarem presentes durante os processos de ensino.

A condução da teoria e prática é discutida por Pissaia e Beschorner (2016) ao evidenciarem que um serviço de ensino e saúde é a melhor maneira de qualificar os estudantes, tendo como base a formação de habilidades e competências inerentes a cada profissão. Ainda assim, o próprio CNE impóe a necessidade de capacitação dos estudantes para uma formação integral e holística para o seu meio de atuação, visto que as capacidades e competências também norteiam todas as acepçóes sobre o tema, principalmente quando instrumentalizam a produção de mão de obra qualificada ao mercado de trabalho (CONSELHO NACIONAL DE EDUCAÇÃO, 2001).

Outro fator importante a ser destacado nas descrições realizadas pelos participantes é a adaptação de práticas, ou seja, tem-se um conhecimento teórico e partindo-se deste, realiza-se uma prática condizente com a necessidade do indivíduo. A afirmação pode ser vista no relato de Q08: "Na teoria adquirimos os conhecimentos baseados em estudos e conhecimento comprovados cientificamente, mas para aplicar esses conhecimentos na prática é necessário pensar e fazer conforme a necessidade da pessoa". O fato de adaptação é ainda fomentado por Q02 que lembra: "Na enfermagem a teoria e a prática andam juntas, mas nem sempre aquele estudo analisado é o melhor pra mim aplicar no hospital, vou ter que buscar alternativas", esse relato induz a um pensamento auto reflexivo do participante.

Para Tannure e Pinheiro (2014) a prática constante de enfermagem pressupóe a realização de adaptações, meios reflexivos que os agentes buscam para oferecer uma assistência resolutiva aos seus clientes. Da mesma forma Paurosi et al (2018) incitam sobre a necessidade de os estudantes estarem abertos a aprender e após, construírem seu próprio conhecimento na prática, pressupondo que há uma diferença entre os dois momentos e espaços distintos.

No contexto de auto reflexão, alguns participantes descrevem suas próprias vivências enquanto estudantes, descrevendo a importância de tê-las, conforme a descrição de Q13: "A parte teórica é passada de maneira clara e dinâmica. A prática ocorre ao longo do semestre, e nas aulas práticas é que podemos relacionar com a teoria estudada em sala de aula". O mesmo participante ainda destaca alguns aspectos em outro trecho: "As aulas práticas sáo realizadas de maneira dinâmica, ocorre diálogo, esclarecimento de dúvidas, visualização de procedimentos, é muito produtiva". O CNE apoia a construção de atividades que permitam a correlação entre teoria e prática, identificando o alto grau de aperfeiçoamento que confere para a formação em enfermagem, visto que vivenciar a realidade em consonância à sala de aula fundamenta seu profissionalismo (CONSELHO NACIONAL DE EDUCAÇÃO, 2001).

A importância de vivenciar a prática mereceu destaque na resposta de Q30: "Na prática vivenciamos as dificuldades, bem como as facilidades de certos procedimentos, é onde descobrimos onde queremos atuar, onde temos afinidade e nos enxergamos". E o mesmo participante complementa: "Os momentos em campo com dificuldades sáo necessários, aprendemos muito com isso, além de identificar coisas que podemos melhorar ao longo da caminhada de enfermeiro". 
Para Magalhães et al (2017), as práticas estão previstas nas Diretrizes Curriculares vista a sua importância para a formação do estudante, e principalmente para que desenvolvam suas capacidades, tidas como de iniciativa individual, incluindo a perspectiva de atuaçáo profissional.

Da mesma forma que os aspectos práticos destacaram-se, os aspectos teóricos foram lembrados pelos participantes. Sobre isso Q17 descreve: "Precisamos da parte teórica, comprovação de evidências científicas para partirmos de um pressuposto de como aplicar esta parte de forma prática". Este embasamento inicial oferecido pelo conteúdo teórico também permeia o relato de Q11: "Como vamos fazer um procedimento sem saber o porquê é indicado e como faz, na verdade as vezes é cansativo, mas quando se presta atenção e entende os objetivos, se percebe que é nossa profissão". A preocupação com a formação em enfermagem foi destacada no relato acima, bem como uma característica relacionada à aula teórica, sendo "cansativa", que por vezes aparece em detrimento às metodologias de ensino empregadas.

A construção de um ensino embasado em disciplinas teóricas e práticas é tida como efetiva e importante para Pissaia e Beschorner (2016) já que promovem a capacitação dos estudantes para o mercado de trabalho e incentivam a interdisciplinaridade. Ainda para o CNE, a partilha entre teoria e prática é defendida junto às Diretrizes Curriculares dos Cursos de Graduação em Enfermagem, tendo-as como fundamentais para a formação crítica e reflexiva dos enfermeiros. Assim geram mão de obra capacitada e motivada para com as necessidades da população (CONSELHO NACIONAL DE EDUCAÇÃO, 2001).

Sobre as metodologias de ensino, Q24 destaca: “As aulas teóricas são boas nessa disciplina, nós estudamos o conteúdo e em seguida fizemos o plano de cuidados, é tipo uma prática em sala de aula, que reforça aquilo que vimos e tira o sono". Tal afirmação referese diretamente a realização de técnicas de ensino que fomentam momentos diferenciados e potencializadores. Paurosi et al (2018) pactuam que a aprendizagem efetiva na área de enfermagem perpassa momentos teóricos e práticos, consonante com o perfil dos estudantes e com as necessidades de reinventar métodos inovadores de correlação entre ambos.

Momentos que potencializam a discussão e construção do conhecimento representam uma abertura ao ensino efetivo, principalmente em saúde, onde as compreensóes necessitam de significados para serem atribuídas às práticas. Um destes fatores é o uso de tecnologias para a compreensão do conteúdo, conforme o relato do participante Q26: "A teoria e prática pode ser muito bem exemplificada por meio da $S A E$, pois nele realizamos o plano de cuidados e melhor ainda, depois praticamos no Tasy, que ajuda a entendermos como será no futuro profissional". O mesmo limiar de compreensão é estendido por Q09: “A teoria e a prática não funciona sem algo que faça uma ligação, aqui na faculdade vejo que a professora relaciona muito o Tasy, aquele sistema que coleta as informaçóes e nos faz aprender a fazer a $S A E^{\prime \prime}$. Percebe-se que os participantes conseguem identificar pontos facilitadores da relação entre teoria e prática, neste caso, a utilização do software Tasy 5 .

5 Tasy é um software de gestão em saúde e que pode ser encontrado no Centro Clínico Univates, serviço pertencente à Universidade do Vale do Taquari - Univates. 
As Diretrizes Curriculares fomentam a utilização de modelos didáticos para a aprendizagem eficaz dos estudantes e conforme menciona Teixeira (2017), a utilizaçáo de ferramentas informatizadas facilita essas demandas. Sob o mesmo limiar, Pissaia e Beschorner (2016) fomentam a utilização do software Tasy para a assertividade na relação entre teoria e prática em cursos da área da saúde, visto a ampla rede de informaçóes e possibilidades de ensino que a ferramenta disponibiliza. Neste sentido, na próxima seção, serão apresentadas reflexôes práticas sobre essa relação entre teoria e prática por meio de mapas mentais.

\subsection{A construçáo de conceitos vivenciados na relação entre teoria e prática na disciplina}

Buscando identificar os pontos fundamentais na relaçáo entre teoria e prática na disciplina de Enfermagem na Saúde do Adulto e Idoso I, parte teórica, os participantes foram convidados a criar mapas mentais em grupos. Os mapas constituem-se de uma ferramenta metodológica que identificará a potencialidade da metodologia didática utilizada por meio da problematizaçáo dos participantes, que após a conclusão da tarefa apresentaram ao grande grupo suas ideias e conceitos.

No que tange a definição de mapas mentais, Moreira (1999) afirma que são diagramas, cujo propósito é demonstrar significados e suas relaçôes simbólicas. Para tanto, não seguem um limiar desejável, e sim o fluxo direciona-se por meio da vontade e inquietação do indivíduo que o compóe. Em consonância a isso, Moreira (1999) defende ainda, a criação de mapas mentais em livre punho, ou seja, a criação realizada em material onde as simbologias, bem como suas ligaçôes, podem ser transpostas, modificadas ou apagadas em qualquer momento.

Os grupos foram reunidos conforme afinidade entre os participantes, com liberdade em sua quantidade, estando todos entre três a cinco estudantes cada. Cada grupo recebeu folhas A4 e a construção do mapa mental ficou sob responsabilidade de cada agrupamento. Ressalta-se desde já, que em todos os documentos analisados as nomenclaturas de Processo de Enfermagem, SAE e Tasy apareceram como peças centrais nas suas compreensōes sobre a relação entre teoria e prática no contexto da disciplina.

A relação entre PE, SAE e Tasy vem sendo estudada há alguns anos por Pissaia et al (2018), em que correlacionam a utilização do processo de trabalho aliados a uma ferramenta informatizada como forma de qualificar a assistência oferecida ao cliente e obter um gerenciamento efetivo em saúde. $\mathrm{O}$ conjunto de nomenclaturas é destacado também no estudo de Pissaia e Beschorner (2016) ao buscar uma alternativa de qualificação do ensino por meio da implantação de um serviço de ensino e saúde, o qual implementou a SAE por meio do software Tasy.

A seguir serão apresentados alguns mapas mentais em formato de imagem: 


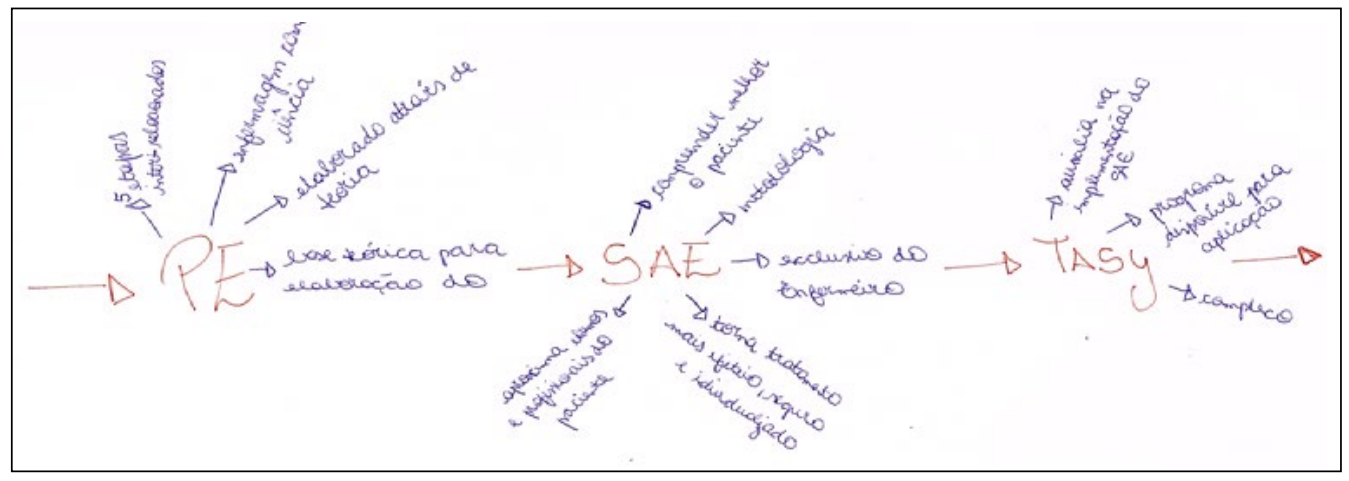

Fonte: Pesquisa (2018).

$\mathrm{Na}$ Imagem 1, visualiza-se a presença dos três pilares centrais da disciplina teórica, o PE, a SAE e o software Tasy. Inicialmente identifica-se que os estudantes preocuparamse em definir uma ordem específica como se fossem alguns passos, sempre precedidos e seguidos de setas horizontais que induzem a uma ideia de continuidade, em consonância a um processo interconectado e interdependente. Tal verificação condiz com os preceitos de etapas ou ciclo argumentado por Tannure e Pinheiro (2014) ao exemplificarem o eixo de utilização do $\mathrm{PE}$, sendo assim condizente com os modelos inseridos na aprendizagem dos estudantes.

O PE figura como uma abordagem teórica, fundamentando a enfermagem enquanto ciência e centrado em cinco etapas e que fundamenta o próximo item que é a SAE, a qual representa uma metodologia, aperfeiçoa a compreensão individual do paciente e o mais interessante, aproxima os alunos e os profissionais dos indivíduos cuidados. A compreensão sobre SAE e PE, bem como sua diferenciação merece destaque principalmente ao citar que se trata de uma metodologia que favorece um olhar holístico sobre o cliente e seu contexto, conforme citado por Andrade e Silva (2017).

A ligação entre SAE e Tasy, ocorre por meio do dizer "exclusivo do enfermeiro" remetendo a ideia de metodologia de trabalho, sendo que o software apresenta-se como complexo, mas que auxilia na implantação da SAE. Condizente com a ideia apresentada, Pissaia et al (2017) identificam in loco que o software Tasy auxilia na implantação da SAE, trazendo a tona um facilitador do processo metodológico de trabalho do enfermeiro. 


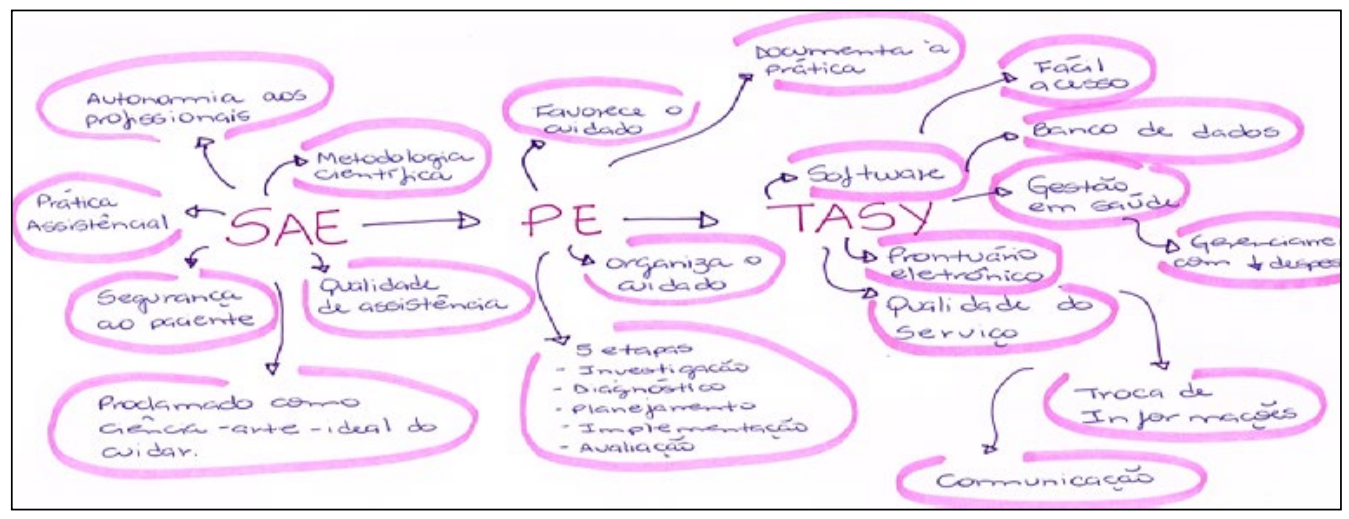

Fonte: Pesquisa (2018).

A Imagem 2 com seus contornos de coloração rosa desloca os três pilares em relação a primeira imagem. Inserindo o PE ao centro de toda descriçáo, precedido pela SAE e sucedido pelo Tasy. Conforme Moreira (2012), o fluxo de ideias presente no mapa mental demonstra a compreensão do estudante sobre determinado tema, sendo imprevisível e por vezes construído inconscientemente. Neste sentido, ao inserir o PE no centro, em uma ação de "desacomodar", os estudantes afloram sua compreensão sobre o tema.

Os participantes ao apresentarem o mapa mental, definiram a SAE como início do processo por delimitar a iniciativa do profissional ou serviço em implantá-la, buscando em suma a autonomia da profissão, qualidade da assistência e oferecendo segurança do paciente. Ao apresentar a SAE no início do mapa mental, o grupo demonstrou o anseio por implantá-la. Tal fato fica evidenciado pelas palavras que são destacadas no entorno da sigla SAE, sendo a autonomia profissional, metodologia científica e qualificação da assistência prestada ao cliente, conforme preconizado por Tannure e Pinheiro (2014).

Após apresentar a SAE, uma flecha horizontal indica a utilização do PE como organização em suas cinco etapas descritas em seguida pelo software Tasy. Ao apresentar o PE no centro, colocam-no como uma ligação metodológica para que a SAE ocorra no Tasy. Consonante a isso, Pissaia et al (2018) afirmam a necessidade de utilizar o PE para realização da SAE na plataforma do software Tasy, buscando uma visão completa e científica sobre o cliente. Software este que figura como prontuário eletrônico, facilitador da comunicação, gerenciador do serviço, banco de dados, dentre outros aspectos. Todas as definiçóes permanecem claras, conforme descrevem Pissaia et al (2018) em seu estudo sobre a aplicabilidade da SAE em uma instituição hospitalar. 
Imagem 3. Os destaques

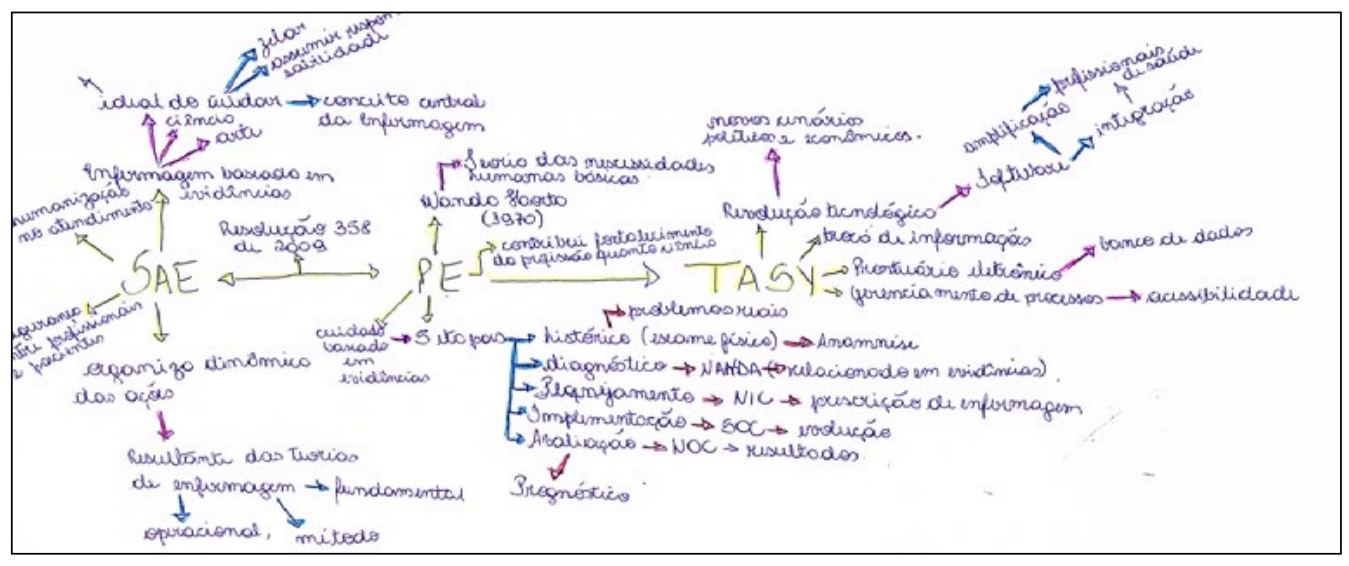

Fonte: Pesquisa (2018).

$\mathrm{Na}$ Imagem 3 os participantes seguem a mesma ordem de itens da segunda imagem. $\mathrm{O}$ destaque fica com as três nomenclaturas em amarelo, o que chama a atenção e enfatiza sua importância no recheado mapa mental construído. Para Moreira (1999), os destaques utilizados em um mapa mental, demonstram a expressividade que tal termo, exemplo ou frase representa aos autores. Em suma, o destaque quer ser visto, chama a atenção ao observador.

Além dos itens que se repetem das demais imagens, identifica-se que os participantes preocuparam-se em delimitar um limiar histórico para o fluxo de ideias, tal fato também norteou a apresentação realizada em sala de aula. Para Teixeira (2017), a concepção histórica de determinado fato lhe confere importância, ao apresentar uma trajetória que acaba por definir traços importantes e um sentido de evoluçáo, quando amparamos a enfermagem em um meio histórico, identificamos não somente os alicerces da profissão, mas sua construção e fundamentação atemporal.

A SAE, por exemplo, é localizada partindo-se das teorias de enfermagem, sendo o arcabouço científico fundamental da área, estando historicamente centrada na Resoluçáo 358 de 2009 a qual define sua obrigatoriedade. Para Tannure e Pinheiro (2014), a SAE permanece sendo visualizada culturalmente como algo obrigatório, em suma o é, no entanto, por traz dessa definição busca-se almejar novos horizontes de compreensão. $\mathrm{O}$ profissional que compreende a SAE como metodologia qualificadora de seu trabalho estará implementando a metodologia em sua prática sem dar contas para a legislação, pois já o faz.

Já, o PE é ligado a Teoria das Necessidades Humanas Básicas de autoria da enfermeira Wanda Horta, em 1970. Identificando as taxonomias NANDA, NIC e NOC e surpreendentemente incluindo ao meio o sistema SOC (Subjetivo - Objetivo - Conduta) para a realização da implementação do plano de cuidados, a utilização das taxonomias aparece com grande força na área da enfermagem. Para Tannure e Pinheiro (2014), esse uso é definido pela constante busca em qualificar as práticas desenvolvidas, seja por meio do registro padronizado ou pela difusão de conhecimentos cientificamente aceitos. 
E por fim, o software Tasy encontra-se como fruto da Revoluçâo Tecnológica e dos cenários políticos e econômicos atuais. Consonante a isso, Pissaia et al (2018) compartilham da mesma percepção sobre os cenários de ascensão do software aos serviços de saúde. Tal fato é evidenciado por Yamamoto, Bandeira-Paiva e Ito (2015) ao articularem ferramentas tecnológicas para a gestão hospitalar do século XXI.

Imagem 4. As múltiplas faces

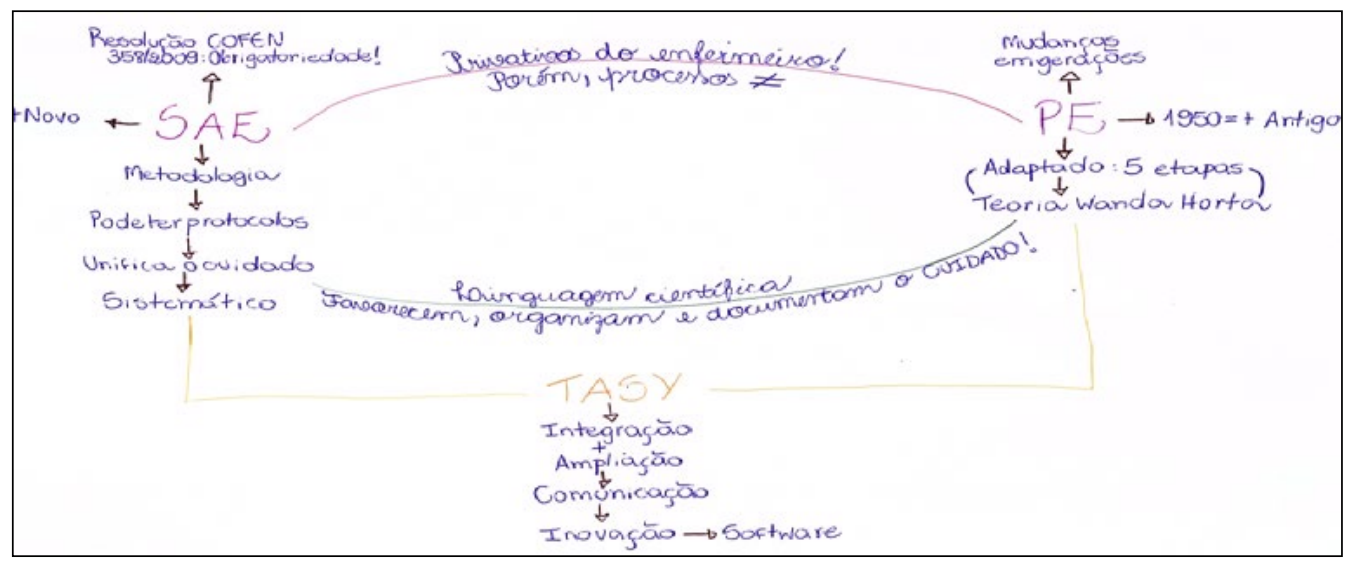

Fonte: Pesquisa (2018).

A Imagem 4 traz o mapa mental diferenciado. Alguns elementos condizem com os levantados por outros grupos, como as características essenciais de cada ponto focal, seu limiar histórico. No entanto, as ligaçóes tornaram-se mais flexíveis e múltiplas. Conforme os participantes, as ligaçóes em flechas indicam continuidade, linhas retas e semicírculos representam as adaptaçóes necessárias aos modelos de trabalho atual, sendo frequente o uso de palavras potencializadoras, como "inovaçáo", "mudanças" e "unificação". Tais palavras aparecem com frequência no estudo de Pissaia et al (2018) ao realizar asserçôes sobre a utilização de sistemas informatizados na construção de um cuidado qualificado, por meio do gerenciamento digital das práticas de enfermagem.

O diferencial neste mapa conceitual que chama a atenção e que não foi exposto durante a apresentaçáo, localiza-se seguindo o semicírculo superior que liga a SAE com o PE e diz "Privativos do enfermeiro! Porém, processos diferentes (utilizando um símbolo)". Esta compreensão de diferença entre os processos de SAE e PE representa a compreensão básica dos conteúdos que por vezes apresentam dificuldade aos estudantes durante a disciplina. Para Tannure e Pinheiro (2014), compreensão básica sobre a utilização do PE e da SAE dignifica a prática profissional, ao passo que tais ferramentas, se utilizadas corretamente oferecem resultados positivos em relação aos objetivos propostos. 


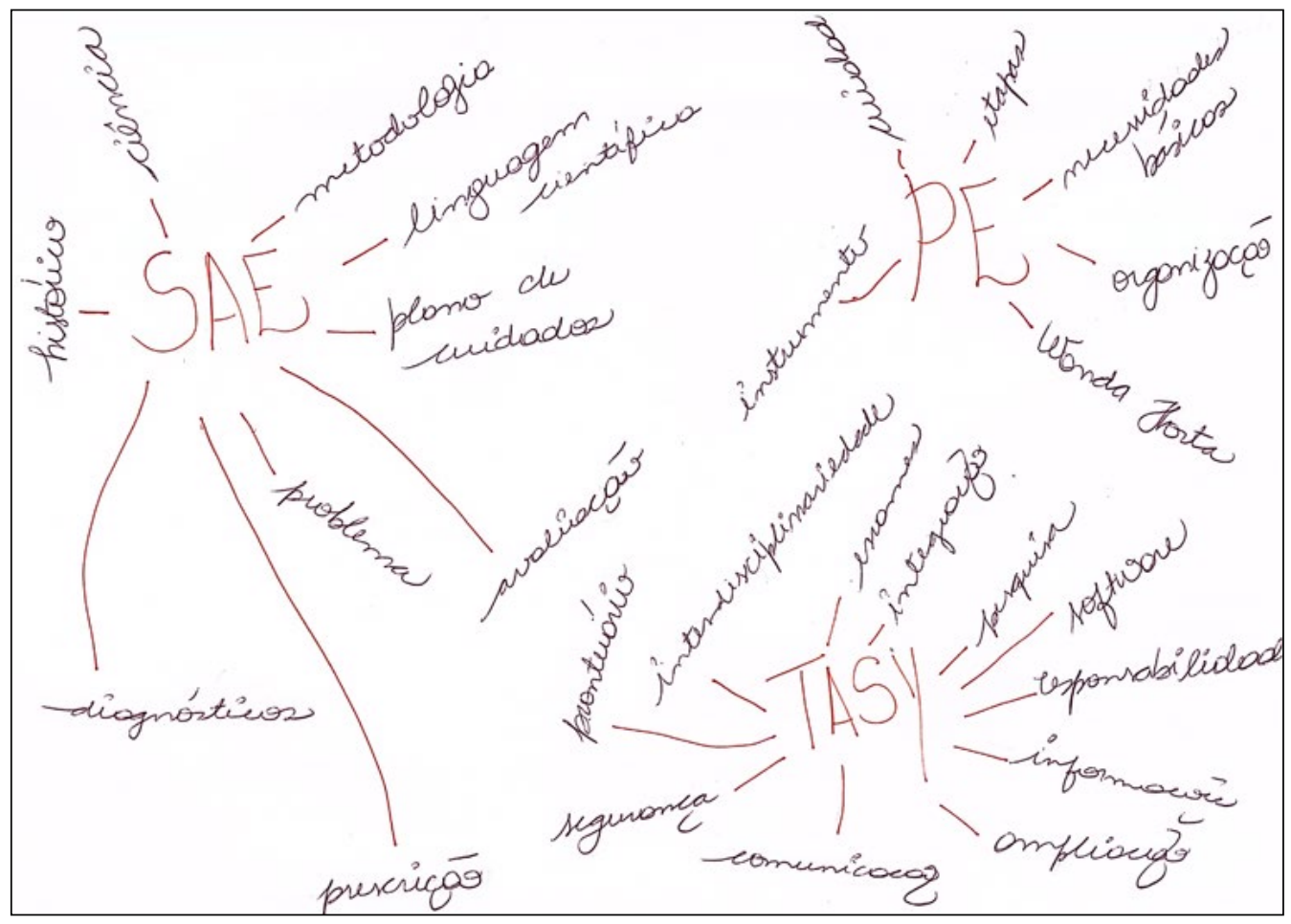

Fonte: Pesquisa (2018).

A Imagem 5 é a última a ser apresentada, sendo que a mesma diferencia-se de todas as demais. A diferença ocorre não pelo conteúdo, pois apresenta termos usuais em todos os demais mapas mentais. O que chama a atenção nesta imagem é a construção do espaço onde se localiza o conteúdo e suas respectivas ligaçóes. As nomenclaturas SAE, Tasy e PE aparecem com letras maiúsculas e fonte em tamanho grande, estando ao centro de palavraschaves únicas e ligadas por linhas sem ponta indicadora lembrando uma espiral.

As palavras-chave condizem com o centro de cada espiral, no entanto não houve ligações entre ambas três. Isso demonstra a dificuldade intrínseca dos participantes em correlacionar o contexto integral dos conteúdos trabalhados, fragmentando-os em pequenos agrupamentos, individualizando-os. Para Moreira (2012), a forma em que fluxos de ideias aparecem ao observador remete à própria compreensão e aprendizagem sobre o tema.

Além desses mapas mentais apresentados, foram entregues e apresentados outros cinco, os quais se assemelham às quatro imagens iniciais destacadas neste estudo. Tal fato às excluiu deste estudo para eximir de repetiçóes no espaço textual.

\section{Consideraçóes Finais}

A problematização proposta com a finalidade de evidenciar a relação entre a teoria e a prática no ensino da SAE demonstrou inúmeros indícios de sua realização e compreensão por 
parte dos estudantes participantes do estudo. Inicialmente, verificou-se que os participantes compreendem a diferença entre a teoria e a prática e sua inter-relaçáo no contexto de ensino em enfermagem, descrevendo a importância durante a trajetória acadêmica e construçáo de um modelo profissional.

Os achados ainda enfatizam a reflexáo dos estudantes sobre a necessidade do professor utilizar diferentes metodologias de ensino para a melhor compreensáo do conteúdo e aproveitamento das disciplinas. Os participantes indicaram a importância de utilizar tecnologias durante as estratégias de ensino, citando o exemplo da SAE com o uso do software Tasy, o qual possibilita a relação entre teoria e prática em relaçáo à disciplina estudada.

Ainda assim, utilizando-se de mapas mentais, problematizou-se a relação entre teoria e prática no ensino da SAE, onde majoritariamente os estudantes trouxeram uma abordagem teórica por meio do PE e o incentivo prático por meio do software Tasy. A presença desses fatores apontando para a compreensão da SAE demonstra a importância do contexto teórico e prático no ensino do conteúdo central, esmiuçando ainda termos e modos indicativos de suas características.

Desta forma, foram introduzidos na discussão os modos de representação dos fluxos de representaçáo, demonstrando compreensão e reflexão sobre a atividade desempenhada e seu contexto acadêmico. Este estudo abre discussóes para a realização de futuras pesquisas que ampliem o grupo pesquisado, bem como o método de pesquisa por meio de estratégias de ensino que evidenciem a relação entre teoria e prática.

\section{REFERÊNCIAS}

ANDRADE, J. S.; SILVA, F. J. C. P. Diretrizes para a sistematizaçáo da assistência de enfermagem hospitalar. In: Congresso Internacional de Enfermagem, 2017.

ARAÚJO, M. M. et al. Assistência à saúde de mulheres encarceradas: análise com base na Teoria das Necessidades Humanas Básicas. Escola Anna Nery, v. 24, n. 3, 2020.

BARDIN, L. Análise de Conteúdo. Tradução: Luís Augusto Pinheiro. São Paulo: Edições 70, 2016.

BRASIL. Conselho Nacional de Saúde. Ministério da Saúde (BR). Portaria 466/2012. Brasília (DF), 2012.

CONSELHO NACIONAL DE EDUCAÇÃO. Câmara de Educação Superior. Resoluçáo CNE/CES N. 3, de 07 de novembro de 2001. Institui as Diretrizes Curriculares Nacionais do curso de graduaçâo em enfermagem. Diário Oficial da República Federativa da Uniāo. Brasília, 09 nov. 2001. Seção 1, p. 37.

DUARTE, A. P. R. S.; VASCONCELOS, M. V. L.; SILVA, S. E. V. A Trajetória Curricular da Graduação em Enfermagem no Brasil. Revista Electrónica de Investigaçáo e Desenvolvimento, v. 1, n. 7, 2017. 
GIL, A. C. Como elaborar projetos de pesquisa. 4. ed. São Paulo: Atlas, 2008.

HORTA, W. A. Enfermagem: teoria, conceitos, princípios e processo. Revista da Escola de Enfermagem da USP, v. 8, n. 1, p. 7-17, 1974.

LAKATOS, E. M.; MARCONI, M. A. Metodologia científica. 6a Ed. São Paulo. Atlas, 2011.

MAGALHÃES, S. M. F. et al. Educação em Enfermagem: conceituando projeto pedagógico na visão de professores. Acta Paulista de Enfermagem, v. 30, n. 3, p. 247 253, 2017.

MARINHO, C. L. A. et al. Necessidades humanas básicas de pessoas em hemodiálise sob à luz da teoria de Wanda Horta. Ciência Cuidado e Saúde, p. 7-7, 2020.

MOREIRA, M. A. Metodologias de pesquisa em ensino. $1^{\text {a }}$ Ed. São Paulo. Livraria da Física, 2011.

MOREIRA, M. A. Teorias de aprendizagem. São Paulo. EPU. 1999.

PAULINO, V. C. P. et al. Formação e saberes para a docência nos cursos de graduação em enfermagem. Journal Health NPEPS, v. 2, n. 1, p. 272-284, 2017.

PAUROSI, D. R. et al. Diretrizes operacionais para uma central de Material e esterilização odontológica: Uma proposta da enfermagem. Revista UNINGÁ, v. 17, n. 2, 2018.

PISSAIA, L. F. et al. Impacto de tecnologias na implementação da sistematização da assistência de enfermagem hospitalar: uma revisão integrativa. Revista de Epidemiologia e Controle de Infecçáo, v. 1, p. 1-20, 2018.

PISSAIA, L. F. et al. Tecnologias da informação e comunicação na assistência de enfermagem hospitalar. Revista de Epidemiologia e Controle de Infecção, v. 7, p. 1-10, 2017.

PISSAIA, L. F; BESCHORNER, C. E. Implantação de um ambulatório de média complexidade no Vale do Taquari/ RS: um relato de experiência. Cinergis, Santa Cruz do Sul, v. 17, n. 4, p. 307-312, out./dez. 2016.

TANNURE, M. C.; PINHEIRO, A. M. SAE: Sistematização da Assistência de Enfermagem: Guia Prático. Rio de Janeiro, Guanabara Koogan, 2014.

TEIXEIRA, E. Em tempos de novas Diretrizes Curriculares Nacionais (DCN) para o curso de graduação em enfermagem. Revista de Enfermagem da UFSM, v. 7, n. 2, 2017. 